\title{
Biomechanical analysis of the human eye after the surgical correction of hyperopia
}

\author{
Svetlana M. Bauer \\ Faculty of Mathematics and Mechanics \\ Saint Petersburg State University \\ Saint Petersburg, Russian Federation \\ Email: s_bauer@mail.ru
}

\author{
Liudmila A. Venatovskaia \\ Faculty of Mathematics and Mechanics \\ Saint Petersburg State University \\ Saint Petersburg, Russian Federation \\ Email: 1_karamshina@mail.ru
}

\begin{abstract}
Changes in the stress-strain state of the cornea and the intraocular pressure (IOP) readings obtained by Goldmann (GAT) and Maklakov (MAT) applanation tonometers after hyperopia correction performed by the most effective in such type of corretion procedures LASIK and IntraLASIK is analized. In the software package ANSYS the elastic system cornea-sclera is presented as two conjugate transversely isotropic spherical segments loaded with internal pressure. The cornea is simulated as multi-layered transversely isotropic elastic shell and the sclera as transversely isotropic homogeneous elastic shell. In order to estimate changes of the IOP readings obtained by GAT and MAT after hyperopia surgery the problem of deformation of the cornea under the load with a flat base is considered. A comparison of the results of two different surgeries, and a comparison of two methods of measuring of the IOP for each of these surgeries is carried out using in all cases the same true intraocular pressure.
\end{abstract}

\section{INTRODUCTION}

A number of studies indicate that refractive surgical correction of hyperopia lags behind in the treating of myopia in efficiency, safety, predictability and stability of the clinical outcomes [1], [2]. Laser keratomileusis in situ (LASIK) is currently considered to be one of the most effective methods for correction of the refractive errors. In hyperopia correction stromal tissue is removed not in the center of the cornea like in myopic correction, but in an annular midperipheral region of the cornea. In the last decade a new form of refractive surgery IntraLASIK (introstromal laser in situ keratomileusis) appeared. The only difference between LASIK and IntraLASIK is the method by which the flap is created. In IntraLASIK instead of mechanical microkeratome with steel blade a femtosecond laser microkeratome is used. Femtosecond laser allows to perform eye correction closer to the periphery of the cornea; this greatly improves the refractive and functional outcomes for patients with hyperopia [2].

\section{MATERIALS AND METHODS}

To estimate the stress-strain state of the cornea after hyperopia correction, a FE model of cornea and sclera as conjugated transversely isotropic spherical segments with different radii and different elastic properties is considered. It is assumed that the composite shell is filled with an incompressible fluid at a pressure $p$. In the simulation the difference in thicknesses and in the elastic moduli of the basic layers of the cornea is taken into account.
According to clinical data [2], it is assumed that during LASIK correction an annular layer of the cornea tissue $\left(L_{\text {ablation }}\right)$ with an inner diameter from 6,0 to $6,2 \mathrm{~mm}$ and an outer diameter from 8,5 to $8,75 \mathrm{~mm}$ is removed with laser beam. It also assumed that during IntraLASIK correction an annular layer of the same width $l_{a b l}$, but with greater inner diameter from 6,4 to $6,6 \mathrm{~mm}$ and an outer diameter from 9,2 to $9,4 \mathrm{~mm}$ is removed. The thickness of the corneal flap created during refractive correction is taken as parameter $h_{\text {flap }}$, the depth of the removed annular layer as $h_{a b l}$. The cut of the corneal flap is also simulated as layer $L_{\text {ablation }}$.

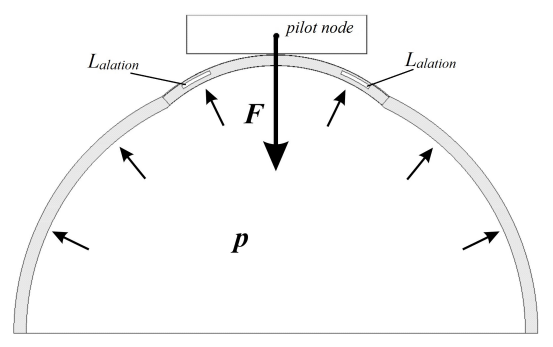

Fig. 1. Finite-element (FE) model of applanation tonometery

In order to estimate changes in the IOP readings obtained after refractive surgery for the correction of hyperopia, the problem of the corneal deformation under the load with a flat base is analyzed, i.e. the model of GAT and MAT applanation tonometers is considered (Fig. 1). In the measurement of the IOP by Maklakovs method, the tonometer with flat foundation (weight $10 \mathrm{~g}$ ) is placed on the cornea. Under the influence of this load, the cornea is deformed and the diameter of the contact area is registered. Goldmanns method is based on measuring the force that must be applied to the fixed central region of the cornea. Flattened area should have a diameter of $3,06 \mathrm{~mm}$, since for this contact area the force of $0,1 \mathrm{~g}$ applied to the tonometer corresponds to the intraocular pressure equal to $1 \mathrm{mmHg}$, therefore the force (in grams) is multiplied by ten and set to be equal to the intraocular pressure. The measurement of the IOP by MAT and GAT is modeled by contact problems in the software package ANSYS. From mathematical point of view the direct and inverse problems are described by one mechanical simulation. Rigid target surface of the tonometer is associated with the so-called pilot node, to which the force $F$ is applied. 


\section{RESULTS}

The calculations were performed for various parameters of the corneal flap and the annular layer of corneal tissue which was ablated during refractive surgery. The elastic moduli of each layer of the cornea in normal direction $E^{\prime}$ are taken 20 times less than in tangential direction $E$, the average modulus of elasticity of the cornea is taken one order less than the modulus of elasticity of the sclera [3].

In Fig. 2 the contour of the deformed cornea after LASIK and IntraLASIK refractive corrections are shown. The inner diameter of the removed annular in LASIK surgery (the ablation zone) is taken as $6,0 \mathrm{~mm}$, during IntraLASIK correction as $6,5 \mathrm{~mm}$. The ablation region width $l_{a b l}$ is taken equal to $1,375 \mathrm{~mm}$, its depth $h_{a b l}$ equals to $172 \mu \mathrm{m}$ [2]. The thickness of the corneal flap $h_{\text {flap }}$ in LASIK surgery is taken as $160 \mu \mathrm{m}$, in IntraLASIK - as $110 \mu \mathrm{m}$. The true intraocular pressure for presented below results equals to $15 \mathrm{mmHg}$.

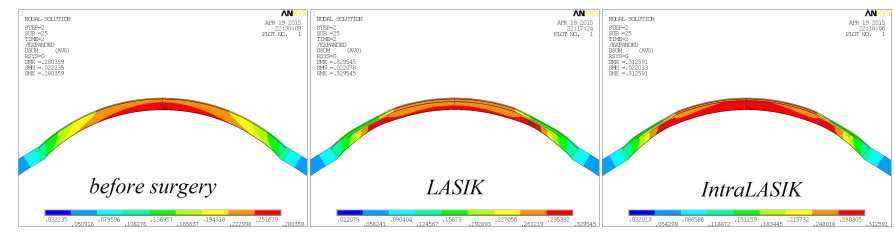

Fig. 2. Deformed cornea before surgery and after LASIK and IntraLASIK refractive correction

In Fig. 3 the strain at the nodes of the finite elements of the inner surface of the cornea before and after LASIK and IntraLASIK surgery is shown for intraocular pressure of 15 and $25 \mathrm{mmHg}$.
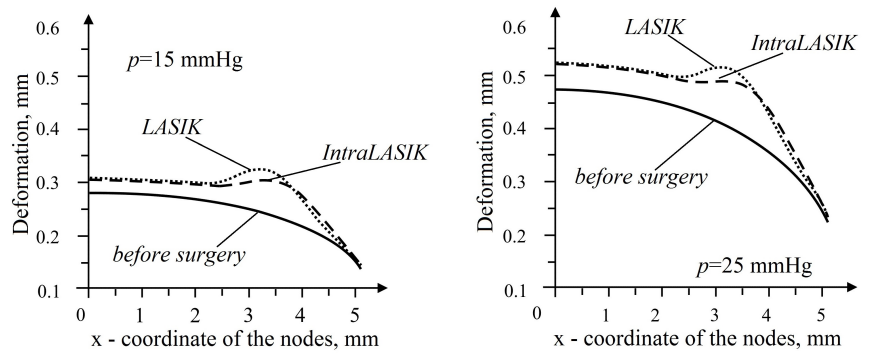

Fig. 3. Deformation in nodes of FE of the inner corneal surface before and after refractive surgery

Calculations carried out for the various parameters of the corneal flap and annular layer of ablation showed that after IntraLASIK surgery, the cornea is deformed more evenly than after LASIK. After LASIK surgery the larger deformations and displacements in the thinning region of the cornea are observed, that explains the lower refractive results obtained in clinical practice [2].

In Fig. 4, 5 the distribution of contact stresses obtained by GAT and MAT (10 g) after LASIK and IntraLASIK surgery are presented. The depth of the ablation region $h_{a b l}$ on the following figures equals to 172 microns, the true intraocular pressure (before loading) is taken $15 \mathrm{mmHg}$.

It is known that Maklakovs method gives not a true, but a tonometric pressure, which is defined by relation $p_{t}=W / S$, where $W$ is the weight of the tonometer (or applied force), $S$ is the contact area [4]. Thus, the resulting tonometric pressure obtained by MAT before surgery equals $22,75 \mathrm{mmHg}$, after LASIK $22,679 \mathrm{mmHg}$, after IntraLASIK $22,672 \mathrm{mmHg}$. These results correspond to the true IOP of $15,3 \mathrm{mmHg}$.

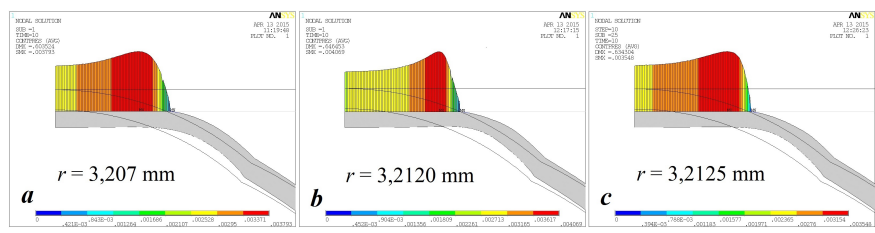

Fig. 4. The distribution of contact pressure obtained by MAT (10 g): $\mathrm{a}$ - before the correction of hyperopia; b - after LASIK correction $\left(h_{\text {flap }}=160 \mu \mathrm{m}\right) ; \mathrm{c}-$ after IntraLASIK correction $\left(h_{\text {flap }}=110 \mu \mathrm{m}\right)$

In Goldmanns method the load of $0,1 \mathrm{~g}$ corresponds to the IOP equal to $1 \mathrm{mmHg}$, thus the true IOP is defined as the ratio $F / g$. The calculation results presented in Fig. 5 correspond to $15,3 \mathrm{mmHg}$ before laser correction, $13,6 \mathrm{mmHg}$ after LASIK and $14,0 \mathrm{mmHg}$ after InraLASIK correction.

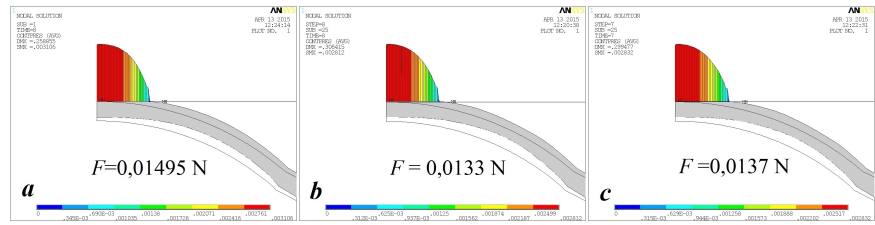

Fig. 5. The distribution of contact pressure obtained by GAT: a - before the correction of hyperopia; $\mathrm{b}-$ after LASIK correction $\left(h_{\text {flap }}=160 \mu \mathrm{m}\right) ; \mathrm{c}-$ after IntraLASIK correction $\left(h_{\text {flap }}=110 \mu \mathrm{m}\right)$

\section{CONCLUSION}

As a result of the FE simulation it was found that reduction in the cornea thickness as a result of annular layer removing during hyperopia surgical correction reduces the flexural rigidity of the cornea and, as a consequence, leads to decrease in the IOP readings obtained by GAT and MAT. According to calculations, the changes in the IOP readings depend on the inner and outer diameters of the annular layer, on the depth of the ablation zone, and on the thickness of corneal flap. Nevertheless it was obtained that changes in the IOP readings obtained by MAT are less than changes obtained by GAT. Also, GAT appeared to be significantly more sensitive to any changes in the geometric parameters of the cornea, which corresponds to the results of the clinical studies [5].

\section{REFERENCES}

[1] L. I. Balashevich. Refractive surgery, St.-Petersburg, Russian Federation, 2002.

[2] L. A. Fedotova, I. A. Kulikova. The advantage of the treatment of hyperopia using femtosecond laser // Health Care of Chuvashia, Cheboksary, Russian Federation, 2009.

[3] E. B. Voronkova, S. M. Bauer, A. Eriksson. Nonclassical Theories of Shells in Application to Soft Biological Tissues. Advanced Structured Materials: Shell-like Structures, Heidelberg, Germany, 2011.

[4] A. P. Nesterov, A. Y. Bunin, L. A. Katznelson. Intraocular pressure. Physiology and pathology, Moscow, Russian Federation, 1974.

[5] L. N. Marchenko, T. V. Kachan. Changes in intraocular pressure after excimer laser correction of refractive errors // Ophthalmology. Eastern Europe, Minsk, Republic of Belarus, 2011. 